THE JOURNAL OF TRANSPORT AND LAND USE http://jtlu.org

VOL. 8 NO. 2 [2015] pp. $87-105$

\title{
Mode use in long-distance travel
}

\author{
Alexander Reichert \\ Technische Universität Dortmund \\ alexander-reichert@tu-dortmund.de
}

\author{
Christian Holz-Rau \\ Technische Universität Dortmund \\ christian.holz-rau@tu-dortmund.de
}

\begin{abstract}
This paper focuses on mode use in long-distance travel. Long-distance travel is responsible for more than 50 percent of climate impact. Nevertheless, it is usually excluded from analyses that examine travel behavior. Whereas studies on daily travel prove that the rural population covers longer distances in daily travel, recent studies (e.g., Holz-Rau, Scheiner, and Sicks 2014; Brand and Preston 2010) show a different picture in long-distance travel. Here, the urban population undertakes more long-distance trips, especially by air. The aim of this paper is to analyze the mode use in long-distance travel in different spatial settings by using multivariate regression models. The (underlying) data derive from a nationwide survey with a sample size of 60,713 respondents, Mobility in Germany 2008 (MiD). A broad range of socio-demographic and socioeconomic characteristics are thereby included as control variables. The results show that even when household income, car accessibility, and education level are considered, the urban population undertakes more long-distance trips, in particular by train and by air. These differences are found in business as well as in private travel.
\end{abstract}

\author{
Article history: \\ Received: November 19, 2013 \\ Received in revised form: April \\ 25,2014 \\ Accepted: April 25, 2014 \\ Available online: July 7, 2015
}

\section{Introduction}

Many studies in transportation focus on travel mode choice and travel distances, but most of them exclude long-distance trips from the analysis, despite the fact that long-distance travel in Germany is responsible for over 50 percent of the climate impact caused by passenger travel (Aamaas, BorkenKleefeld, and Peters 2013). Additionally, transportation is responsible for other ecological costs like land consumption. The ecological costs differ considerably between different modes. For long-distance travel, environmentally harmful transport modes like airplanes or cars are the most regularly used options. There is, in particular, no viable alternative to airplanes when a certain distance is exceeded. In most European countries, aviation is the dominant mode for travel distances greater than 400 kilometers (KITE 2008). A pronounced increase in travel of all kinds, for both personal and business purposes, can be seen throughout the whole world (Frick and Grimm 2014). According to Airbus (2012), plane trips measured by passenger numbers increased by 53 percent between 2000 and 2011 . Due to increasing globalization and the development of new technologies in the mobility sector and in virtual mobility, it is expected that the transnational network will continue to grow and with it the importance of long-

Copyright 2015 Alexander Reichert \& Christian Holz-Rau

http://dx.doi.org/10.5198/jtlu.2015.576

ISSN: 1938-7849 | Licensed under the Creative Commons Attribution - Noncommercial License 3.0

The Journal of Transport and Land Use is the official journal of the World Society for Transport and Land Use (WSTLUR) and is published and sponsored by the University of Minnesota Center for Transportation Studies. This paper is also published with sponsorship from WSTLUR and the Institutes of Transportation Studies at the University of California, Davis, and University of California, Berkeley. 
distance travel and its impact on society and the environment.

Despite the increasing importance of long-distance travel for environmental policies, only a few studies and surveys containing analyses of long-distance travel and long-distance travel behavior exist. Whereas some studies have considered socio-demographic and socioeconomic influencing factors on mode choice (e.g., Georggi and Penyaja 2001; Mallet 2001), less research has focused on the role of the built environment. The literature reveals that the share of daily travel trips undertaken using environmentally friendly modes is greater in urban areas than in suburban or rural areas. Additionally, urban dwellers cover shorter distances in daily travel (e.g., Stead, Williams, and Titheridge 2000; Boussauw and Witlox 2011). This favors the development of compact, dense, and mixed land-use urban structures. Nevertheless, studies that include long-distance travel show contradictory results. In contrast to daily travel habits, inhabitants from dense, urban areas tend to undertake long-distance trips more frequently. Furthermore, they also cover longer distances (Holz-Rau, Scheiner, and Sicks 2014), which may counterbalance their better climate balance deriving from daily travel. The analysis by Holden and Linnerod (2011) supports this notion. The study demonstrated that Oslo's citizens travel more often by air for leisure activities than suburban or rural dwellers from the surrounding area. The question remains: Do persons from urban areas show their environmentally friendly behavior in long-distance travel as well? Do they relinquish use of a car and use the public transport system more often or/and can we also confirm the findings from Holden and Linnerod (2011)? Are there similar or deviant results if the analysis does not focus on a small region such as in recent studies but instead examines a nationwide research area (in our case: Germany), which contains a broad range of different types of spatial areas?

To answer this question we use the national survey "Mobilität in Deutschland" (MiD) from 2008, which contains a dataset on long-distance travel alongside the daily travel data for the first time. Furthermore, the survey provides information on the socio-demographic and socioeconomic attributes of respondents and the spatial attributes of their residential locations. Socio-demographic and socioeconomic characteristics can thus be considered while analyzing mode use in different spatial settings.

The next step is to identify potential influencing factors for long-distance travel behavior, especially mode use. The state of research is first considered to elaborate on such factors. From this basis, multiple hypotheses are then developed. These are verified by using a multivariate data analysis based primarily on different regression models. Taking into account different travel purposes, we also divide our analysis into private and business travel. In considering long-distance travel differentiated by mode use, we follow up a study from Holz-Rau, Scheiner and Sicks (2014) that analyzed the distances covered in daily and long-distance travel using the same dataset (MiD).

\section{State of research}

There are to date few research studies that concentrate on long-distance travel and mode choice on longdistance trips. Expanding the research background can be achieved by including studies that deal with mode choice/use in daily travel. In most households where no car is available for daily travel, there will similarly be no car available for long-distance trips. Drawing conclusions from daily travel research in this way generates more input. Mode choice is influenced by the characteristics of a person but also by framing conditions like the state of transport infrastructure or the accessibility and provision of shops, educational institutions and workplaces at the residence. Furthermore, it can be assumed that the subjective dimension, e.g., lifestyles, values and preferences, also has an impact on travel behavior (Bagley and Mokhtarian 2002; van Acker, Witlox, and van Wee 2007). The following section is divided into two parts. First, the paper presents the influence of socio-demographic and socioeconomic characteristics. Second, it focuses on spatial attributes at the residence. 


\subsection{Socio-demographic and socioeconomic attributes}

As highlighted in many studies, the socioeconomic background of a person has a great influence on travel behavior. Socio-demographic influencing factors (gender, age, employment, household structure) and socioeconomic (income and education) affect participation in and the distances covered in daily and long-distance travel in a similar way (Holz-Rau, Scheiner, and Sicks 2014). One of the strongest influencing factors is the income of the person or the household. This is positively associated with the distances covered in daily and long-distance trips as well as with the frequency of private and business trips (Frändberg 2009; Holz-Rau, Scheiner, and Sicks 2014; Limtanakool, Dijst, and Schwanen 2006). The most significant differences between low- and high-income groups are discovered by analyzing business trips, which mainly occur among high-income groups (Hjorthol 2008; Zumkeller et al. 2005). Regarding mode choice, car and train use increases with income (Limtanakool, Dijst, and Schwanen 2006). However, due to the higher car ownership rate in high-income households, car use in long-distance travel is expected to increase more than train use with increasing household income. In contrast, lower-income groups are more dependent on public transport (Mallet 2001). Airplanes are mainly the mode choice of higher-income groups (Georggi and Pendyaja 2001; Korbetis, Reary, and Grace 2006). Another important influencing factor is the education level of the person. Even when income is considered simultaneously, higher levels of education are related to greater participation in travel and longer distances being covered in daily and especially in long-distance travel (Holz-Rau, Scheiner, and Sicks 2014).

Differences in mobility behavior are associated with aspects of gender. Although convergence has taken place in recent decades, there is still a measurable difference in mobility behavior between males and females in Germany (Holz-Rau, Scheiner, and Sicks 2014; Zumkeller et al. 2005), as well as in other European countries (Frändberg and Vilhelmson 2003; Limtanakool, Dijst, and Schwanen 2006), with regard to long-distance travel frequencies or distances. However, these differences are less distinct among the young cohorts (IFMO 2011). Similar results have been found in analyses of daily travel (Crane 2007; Hjorthol 2008). Significant differences have been discovered with regard to business trips, especially those undertaken by air (e.g., Addante 2001). In business travel, women travel considerably less frequently than men. Analysis of the $\mathrm{MiD}$ reveals that differences (i.e., men cover longer distances) in long-distance travel result exclusively from business trips. There is no indication of a gender gap in private long-distance travel (Holz-Rau, Scheiner, and Sicks 2014). With regard to mode choice, women use the car less frequently in daily travel (Bühler and Kunert 2008; Hjorthol 2008), so this can be expected for long-distance travel as well.

Households with children are also car-affine (Bühler and Kunert 2008). According to Limtanakool, Dijst, and Schwanen (2006), long-distance trips occur less frequently in these households. Nevertheless, it can be expected that households with children prefer the car for their long-distance trips. Single households will be more dependent on public transport due to the high acquirement and maintenance costs of a car. Whereas private trips are mainly undertaken with all household members, business trips are conducted separately from the household (Zumkeller et al. 2005). We therefore expect that household composition primarily affects private trips whereas an individual attribute like gender influences business trips.

Analyses of climate-relevant emissions in long-distance travel aggregate mode use and distances according to one parameter. The socio-demographic effects, identified by Brand and Preston (2010), correspond well to recent analysis of participation, mode use, and distances, but they do not relate to the single behavioral level. 


\subsection{Spatial attributes at the residence}

Spatial conditions influence mode choice in daily and long-distance travel due to differing accessibilities to various transport modes and to destinations. On average, inhabitants in densely settled regions have shorter trips and tend to undertake more trips on foot or by bicycle (Brownstone and Golob 2009; Boussauw and Witlox 2011; Stead, Williams, and Titheridge 2000). Furthermore, high density is a prerequisite for a viable, attractive public transport system (Wiedenhofer, Lenzen, and Steinberger 2007). The public transport system is therefore used more often in densely settled areas at the expense of the car (Brownstone and Golob 2009; Naess 2011; van Acker and Witlox 2010). Accessibility to a light rail station and a nearby train station especially foster the abandonment of car ownership (Naess 2011; van Acker and Witlox 2010). On the other hand, well-developed car infrastructure (e.g., parking spaces in the inner city) facilitates car use (Zhang 2004). It should be emphasized that the differences observed in travel behavior are also part of a self-selection process (see below). The configuration of the transportation system of a city can also have an influence on mode use in long-distance travel. A study from García-Palomares, Gutiérrez, Martín and Román (2014) compared the competitiveness of highspeed trains versus air travel in the Madrid-Zaragossa-Barcelona corridor (trip length: 621 kilometers). Thereby, the study has shown that spatial competitiveness is affected by the access time to terminals, which especially depends on the chosen access mode. On the one hand, the access to a suburban rail network station increases the competitiveness of the high-speed train. On the other hand, an increase in car accessibility promotes the modal competitiveness of air travel.

In contrast to daily travel, there is little research on the influence of the built environment on mode choice in long-distance travel. In general, Holz-Rau, Scheiner and Sicks (2014) found that residents of urban areas undertake more long-distance trips. The study postulates a number of explanations for this. First, it assumes that "cities function as nodes in a national or global urban system" so they may operate on a larger scale. Second, the better accessibility to long-distance travel infrastructure may encourage people to undertake more long-distance trips. Third, these individuals have more dispersed social networks that need personal contacts. Such urban lifestyles may also include "escape trips from the city." With these assumptions in mind, more trips can be expected with every mode. This corresponds with the findings of Brand and Preston (2010), who analyzed Oxford and its surrounding area. This study found that persons from the large urban area produce more emissions in transport than the sample average (areas of comparison: medium-urban, small-urban, and rural). Heinonen et al. (2013) adds that urban dwellers produce more emissions for recreational purposes than the rural population. This is a result of more air travel (Brand and Preston 2010; Heinonen et al. 2013; Holden and Linnerod 2011). In contrast to this, the findings of daily travel research suggest that lower car ownership and lower car use by inhabitants of dense urban areas also result in less long-distance car travel by this group.

Furthermore, these assumptions indicate another important influencing factor: residential selfselection. The differences observed between urban and rural areas may not only be caused by the built environment. To a certain extent they may also result from households' residential location choices, e.g., neighborhood preferences, but also travel preferences (Moktharian and Cao 2008). This would support the third assumption by Holz-Rau, Scheiner and Sicks (2014), namely that urban lifestyles play an important role in travel behavior over long distances. Even if self-selection issues are at play, one may maintain the hypothesis derived from theoretical considerations and empirical studies that there is a link between the built environment on the one hand and mode choice and trip distances on the other. 


\subsection{What is new?}

In contrast to former studies (e.g., Brand and Preston 2010; Heinonen et al. 2013; Holden and Linnerod 2011; Holz-Rau, Scheiner, and Sicks 2014; Limtanakool, Dijst, and Schwanen 2006) with a focus on distance and mode use in long-distance travel, we expand the analysis with regard to the evaluated dependent variables, inclusion of control variables and the scope of the analyzed data. Our analysis is based on a three-stage process.

- The first step examines whether at least one long-distance trip is undertaken using the mode under consideration. In contrast to other studies focusing on the share of mode use (e.g., Limtanakool, Dijst, and Schwanen 2006), this analysis allows additional conclusions. For instance, in the case of increased train use by persons from cities with an inter-urban rail station, we can analyze whether this results from shifting (substitution of car trips) or greater trip frequency.

- The second step of the analysis focuses on the distances covered over a year by persons with long-distance trips differentiated by mode. Whereas the first step examines (among other things) how often urban dwellers participate in long-distance travel compared to individuals from smaller municipalities, this step allows testing of whether the destinations of urban citizens are also farther away. Both steps rely on significance tests to verify the effects.

- The third step builds on the first two steps and summarizes them on a descriptive level. The effects represent differences in covered distances per person and year by mode in long-distance travel. They are thus in their original scale and easy to understand and interpret.

The analyses are constructed in a similar way to the comparative analysis of distances in daily and longdistance travel (Holz-Rau, Scheiner, and Sicks 2014), but they are differentiated by mode use in longdistance travel. Control of the socio-demographic and socioeconomic effects is more detailed than in most comparable studies (e.g., Brand and Preston 2010; Heinonen et al. 2013; Holden and Linnerod 2011), resembling the study by Limtanakool, Dijst, and Schwanen (2006). Because of the recent analysis (Holz-Rau, Scheiner, and Sicks 2014), it seems necessary to test some interaction terms, especially between gender and age with the different employment categories.

Our analyses are based on a German-wide household survey on travel behavior, which has a large sample size (see below). This approach thus goes beyond that of studies on a regional level, e.g., Brand and Preston (2010). Additionally, and in contrast to Limtanakool, Dijst and Schwanen (2006), our analyses consider international trips, which are of particular climate relevance, and include national and international air travel.

With regard to framework conditions, the access to spatial data is severely limited in Germany due to data privacy regulation. The data, therefore, are not geocoded. The municipalities are differentiated by a small number of objective attributes like federal state, municipality population size, density of the area, or accessibility to an inter-urban rail station. Supplementary data cannot be added because the names of the municipalities and their municipal codes are not available. Other studies can hence draw on considerably more differentiated data. Nevertheless, the available data allows insightful analyses of the influence of spatial differences on long-distance travel.

\section{Hypotheses}

As described in the previous section, various socioeconomic and spatial attributes influence travel behavior in daily and long-distance travel. The population of larger municipalities undertake more and longer long-distance trips, even when socio-demographic and socioeconomic characteristics are taken into consideration (Holz-Rau, Scheiner, and Sicks 2014). They thereby use trains and airplanes at a 
higher rate (Brand and Preston 2010; Heinonen et al. 2013; Limtanakool, Dijst, and Schwanen 2006). The following section presents hypotheses based on the findings of current research (see previous section). The focus is on differences in travel behavior that are related to differing spatial circumstances. The hypotheses are:

1. Inhabitants from dense, urban municipalities with a well-developed public transport system undertake more long-distance trips by airplane and train than the rural population.

In common with hypothesis one, we also express the second hypothesis as unidirectional.

2. Inhabitants from dense, urban municipalities with a well-developed public transport system undertake fewer long-distance trips by car than the rural population.

At the same time, we control the rate of motorization of the households (see below). Hence, the question that will be answered is: Do urban dwellers with access to a car in the household use the car less frequently in long-distance travel than residents of a smaller municipality with a car in the household? We do not ask whether urban dwellers use the car less frequently than persons from smaller municipalities. In our case, spatial differences in the rate of household motorization are placed outside the bracket. Thus, we expect, if at all, small effects. Without consideration of these spatial differences in household motorization, we would expect significant effects.

Control variables are needed to verify hypotheses one and two. These focus on the influence of socio-demographic and socioeconomic attributes.

3. There are significant differences in terms of travel frequency and distances covered for all modes in long-distance travel due to employment, education level, and household income. Fully employed, highly educated persons with a high household income use every mode more frequently, but especially planes and cars. The differences become larger when the focus is solely on business trips.

4. The gender gap in travel behavior is not yet fully dissolved. With regard to business travel, men travel more frequently and cover longer distances using all modes, but especially the car.

5. Multi-person households, especially those with children, use the car more frequently. In contrast, single households are expected to display a higher use of public transport modes.

\section{$4 \quad$ Data and methodology}

The dataset for this analysis is the MiD (Mobility in Germany) survey from 2008. It is a nationwide household survey of 25,922 households totaling 60,713 respondents in Germany who were interviewed by phone concerning their travel behavior. Germany has no nationwide register of residents. Therefore, the survey used a stratified random sample. The first step involved the selection of the municipalities; these were chosen by settlement structure and administrative districts. Inhabitants of the chosen municipalities were then randomly drawn and every household member questioned. The response rate was 20.9 percent (INFAS and DLR 2010). Daily trips were surveyed by one-day trip diaries, long-distance trips were recorded retrospectively for three months. The last three journeys within the three months were recorded with detailed information including purpose, distance covered, and chosen mode of transport on each journey. In cases where household members were not accessible, other household members filled out a proxy interview on their behalf. Information on long-distance journeys is missing from these interviews and they are thus excluded from the analysis, as are persons under the age of 18 
years and conscripts ${ }^{1}$. Finally, persons with incomplete data entries are also taken out of the analysis sample. The remaining sample includes 34,194 respondents.

\subsection{Definition of long-distance travel}

To perform the analysis it is essential to define "long-distance travel" and to distinguish between daily and long-distance travel. Numerous definitions have been applied in previous surveys. Some distinguish long-distance from daily travel by distance. The most commonly used distance is around 100 kilometers (one-way straight line), e.g., in the European-wide DATELINE survey (Brög et al. 2003). Other surveys use travel duration as a variable to differentiate between short- and long-distance trips. As mentioned above, the MiD 2008 has a separate dataset for long-distance travel that only includes trips with at least one overnight stay outside the place of residence but does not define a limitation by trip length. Trips of less than 100 kilometers are consequently excluded in the analysis. These represent 6.2 percent of all trips, but only 0.5 percent of the distance covered within the whole sample.

\subsection{Analysis approach and dependent variables}

As mentioned above, the long-distance journeys in the MiD 2008 were surveyed retrospectively in a separate questionnaire module with a maximum of three detailed recorded trips per person within a quarter of a year. The respondents estimated the distances. There is no information recorded on destinations. In addition, the module provides the sum of all long-distance trips within the quarter. Hence, we estimate the distance covered by a person over a quarter of a year from the three detailed reported trips and the total number of trips. In total two different dependent variables are used in the analysis. First, the likelihood of participation is estimated using the question: Did the person undertake a long-distance journey within the three surveyed months? Second, the distance covered by mobile persons over the quarter of the year is estimated. By combining these two variables it is possible to analyze an average covered distance for different groups of people.

For this kind of data, regression models are suitable. However, the assumption of normally distributed residuals is violated due to numerous persons who do not travel during the three months reported. Many of these individuals may, however, make a trip at some point in the year. This means that the data is censored and zero-inflated. The Tobit-model is one possible option to handle these limitations. It involves a one-stage procedure to estimate a selection equation (does the person undertake a long-distance trip?) and an outcome equation (the distances covered in long-distance travel) simultaneously (Brüderl 2000). However, the Tobit-model presumes that selection and outcome are influenced by the same explanatory variables (Kennedy 2010; Stewart 2009). In our case we cannot fulfill this condition because variables like car availability may influence the selection (does the person undertake a car trip?) but not necessarily the outcome (distances covered by person who undertakes a car trip).

The second option is a two-stage Heckman model (Stewart 2009). The first step is a Probit model (selection). In the second stage, the value of the dependent variable is estimated using a linear regression model including the factor Lambda (inverse Mills ratio) that corrects for the selection bias (Brüderl 2000). This procedure requires the definition of an explanatory variable that must be excluded from the second step to avoid collinearity between Lambda and the other explanatory variables (Winship and Mare 1992). If Lambda turns out to be insignificant, the selection correction does not contribute to the improvement of the coefficient estimates, and the specific feature of the Heckman model is not required (Wooldridge 2013). In our case, the Lambdas were not significant and do not improve the model. Therefore, we decided to use a slightly different approach that is easier to interpret and more comprehensible. We pick up the two-step approach with a logit-model and OLS-model but relinquish Lambda.

${ }^{1}$ In the case of conscripts or those doing their civilian service, place of residence does not match with their actual place of daily living. 
The first step is the selection equation, which is a logistic regression for every mode (models $1-4$, 13-16). Due to the fact that an individual may use more than one mode within the three months reported, it is necessary to use a single regression for each mode rather than a multinomial regression for all modes. The question to be answered is: Did a person use the mode during the three months reported or not? In this case it does not matter how often the person makes a journey or how much time the person invests for a trip. To reduce the likelihood of first type errors due to the amount of explanatory variables, the significance levels of this regression model are Bonferoni-Holm corrected on a 5 percent level. These significance corrections calculate local alpha levels from the ratio between the global alpha level (5 percent) and the number of tests performed. This leads to a more rigid level of significance from one test to the next (Holm 1979).

The second step is the outcome-equation (models 5-8, 17-20). In this analysis, only persons who designated at least one reported long-distance trip with the analyzed mode are considered. The aim of this step is to work out differences between the trip distances of the mobile persons (those who made at least one long-distance trip). Therefore, the distances covered by the long-distance trips are extrapolated to one year (i.e. multiplied by four). As trip frequencies — in particular for non-daily, relatively rare activities - tend to be overestimated (Schlich and Schönfelder 2001), we limit the number of long-distance journeys to a maximum of 10 in a quarter of a year. A standard OLS regression model with logarithm distances is used for the significance tests (Bonferoni-Holm corrected). In combination with these significances (see stars in models 5-8, 17-20), we present the effects sizes of a non-logarithmic regression (see values of the models 5-8, 17-20). We think that these original scaled effects are more informative than the logarithmic effects sizes.

The third step is a descriptive approach (models 9-12, 21-24) that illustrates the results by combining the first two steps using a linear regression with the distance covered by all persons (mobile and not mobile). In this context, persons without long-distance trips figure in the analysis with no distance covered. In contrast to the first two steps, the distances are weighted. The respondents were surveyed irregularly over the year, but the number of long-distance trips can vary over the year (e.g., more holiday trips in the summer). Thus, the analysis is weighted by weekday and month to avoid an over- or underestimation. The last step of the analysis dispenses with significance tests.

Furthermore, a differentiation of business and private travel expands the analysis. It is important to analyze whether the differences observed result from only one or both kinds of travel. For reasons of comparability, the analysis is carried out in a similar way to the analyses of overall long-distance travel. It has to be mentioned that some of the linear regressions of the business travel analysis in particular have no significant values owing to overly small samples. It is quite natural that, e.g., non-employed persons usually do not participate in business travel and thus have no documented distances for business travel. Hence the analyses of business trips show greater spikes.

The results of this expansion are shown in the models 13-24, which present the analysis of business travel. The paper dispenses with a presentation of private travel because there are no major differences compared to the analysis of long-distance travel. This results from the fact that nearly 83 percent of longdistance trips have a private purpose. Only 17 percent are business travel. Nevertheless, it is possible to estimate the distances of all persons in this paper by subtracting the business distances from the total.

\subsection{Explanatory variables}

The explanatory variables are taken from the existing questionnaire module with socioeconomic and spatial attributes and are intended to focus on the hypotheses and the findings from the state of research. The explanatory variables are put into three categories: individual attributes, household attributes, and the spatial attributes of the residences. The discrete explanatory variables are built up as dummy variables 
because of the regression model design. Building on the literature review, we identify a number of individual attributes. Four of them are then checked in the model:

- Employment

- Level of education (only persons who finished education)

- Gender as an interaction with employment

- Age as an interaction with employment

The MiD does not offer detailed information on the professions of those surveyed but provides information on individual working hours per week. Hence, we can differentiate between those in full and part-time employment and the non-employed. Furthermore, non-employed persons are divided into different sub-groups (persons in apprenticeship or education, housewives and househusbands). Persons over the age of 70 are also in a separate group (retired persons). Educational background is difficult to measure. In our case, we decided to use educational attainments to define different education levels (i.e. university degree, university entrance qualification, medium standard-secondary school, basic school, or no qualification). As apprentices do not finish education and therefore have to be excluded from this attribute, education is described as an interaction with employment.

The attributes age and gender are not used as main effects but are used in interactions with employment status. Holz-Rau, Scheiner and Sicks (2014) demonstrated that differences due to gender aspects mainly occur among the employed because these persons show a different number of business trips. The reason for using age in an interaction is similar to that for using education level. With the category "person in apprenticeship," a category that is influenced by age aspects already exists. As shown in the literature review, individuals under the age of 40 tend to use the public transport system more frequently, so we decided to separate employees younger and older than 40 years. Furthermore, we differentiate between non-employed persons younger and older than 70 years.

Household attributes:

- Household income

- Household type

- Number of cars per driver's license

In the MiD data, household income is not a linear variable. The households are categorized into five income groups. To be classified into a higher category, larger households need a smaller income per person in the household than smaller households. The household type differentiates between single and multi-person households. Both categories have different interactions. Single households are divided into the age-related subgroups that we use for a differentiation of employees and non-employees (younger than 40 years, between 40 and 70 years, 70 years and older). It is expected that a young single household will display different travel behavior than a pensioner living alone. In multi-person households we differentiate between households with and without children to clarify the impact of a child on long-distance travel behavior.

The last attribute is the number of cars per driver's license. In the regression model three different groups are used: household(s) without a car (non-motorized), with at least one car but less than one car per driver's license (part-motorized) or at least as many cars as drivers' licenses (full-motorized). 
Spatial attributes at the residence:

- Municipality population size

- Density of the region

- Accessibility to inter-urban rail services

The MiD 2008 does not provide geo references, but includes some spatial attributes of the residence. The analysis of municipality population size delivered important results in a recent analysis (Holz-Rau, Scheiner, and Sicks 2014). The different municipalities were first divided into six different categories. After examining our initial results, however, we reduced the categories to four because of the small differences between some categories. Cities with more than 500,000 inhabitants (13 cities) comprise the first category. The second group consists of small and mid-size cities with 50,000 to 500,000 inhabitants, followed by municipalities with 5,000 to 50,000 inhabitants. Municipalities with less than 5,000 inhabitants are put into the last category.

In addition, two interactions that only focus on municipalities with less than 500,000 inhabitants are constructed. The first one serves to analyze the density of these regions. The regions are already classified into three groups according to density. Agglomerations have the highest density and rural areas the lowest density; urbanized areas are the medium category. The question behind this variable is: Despite the lower municipality population size, is the municipality located in an agglomerated area or is it part of a more rural area? Second, access to inter-urban rail services is analyzed by measuring the time necessary to travel by car to the nearest inter-urban rail station. Thereby, only the time needed to travel between the cities is calculated. This means that if a person lives in a city with an inter-urban rail station, it is assumed that travel time is below 10 minutes. Because of this fact, interactions are indispensable. Municipalities with more than 500,000 inhabitants are always agglomerations with inter-urban rail stations, so these cities have to be excluded from these two spatial attributes. In particular, the derivation of the variable accessibility of an inter-urban rail station is not ideal because of the missing geo references and the focus on access by car. Nevertheless, it is a centrality rating for the residence and provides information on the influence of access to public transport.

\section{$5 \quad$ Results}

\subsection{Descriptive analysis}

The following part of the paper presents the descriptive analysis. It focuses mainly on the dependent variables used in the regression models and thus provides initial indications for the analysis of spatial influencing factors on mode use.

An examination of the reported trips (only three trips per person are reported in detail, see above) reveals that a number of trips without information on mode use are included in the sample. Half of the respondents do not undertake a long-distance trip within the three months reported (see Figure 1) and only 7 percent do more than three trips. Nevertheless, 7830 of 37,152 (21 percent) trips are not reported in detail because of the group of highly mobile persons. The remaining size of the sample includes 29,322 trips reported in detail, undertaken by 17,114 different respondents. 


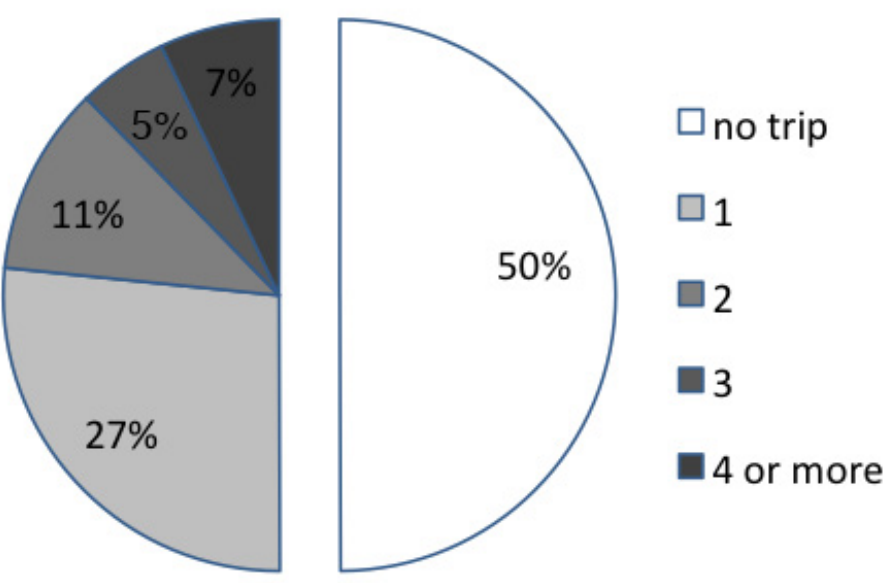

Figure 1: Number of long-distance trips per person (own calculation based on MiD 2008)

The majority of the reported long-distance trips, over 60 percent, are by car (see Table 1). Nearly 70 percent of mobile persons undertake at least one trip by car. It is the favorite mode for all purposes even though the share in business travel is lower (52.6 percent). About 35 percent of respondents make at least one car trip. The train is used for 16.4 percent of all trips with a higher share in business travel (22.9 percent) than in private travel (14.9 percent). Only 14.6 percent of long-distance trips are by air. Nevertheless, due to the high trip distances, it is the mode with the most kilometers covered (on average: 3772 kilometers per person per year) in this sample. Other modes like ships, buses or bicycles, are not analyzed in detail because of the small number of trips (only 1820 of the respondents recorded a trip by ship, bicycle, or other mode).

Table 1: Reported long-distance trips by mode (own calculation based on MiD 2008)

\begin{tabular}{|c|c|c|c|c|c|c|c|c|c|}
\hline & by car & in $\%$ & by train & in $\%$ & by air & in $\%$ & $\begin{array}{l}\text { by other } \\
\text { modes }\end{array}$ & in $\%$ & Total \\
\hline Number of reported trips & 18150 & $61.9 \%$ & 4819 & $16.4 \%$ & 4272 & $14.6 \%$ & 2081 & $7.1 \%$ & 29,322 \\
\hline private purpose & 15230 & $64.1 \%$ & 3550 & $14.9 \%$ & 3065 & $12.9 \%$ & 1924 & $8.1 \%$ & 23,769 \\
\hline business purpose & 2920 & $52.6 \%$ & 1269 & $22.9 \%$ & 1207 & $21.7 \%$ & 157 & $2.8 \%$ & 5,553 \\
\hline Persons with at least one trip & \multicolumn{2}{|c|}{11,913} & \multicolumn{2}{|c|}{3,480} & \multicolumn{2}{|c|}{3,454} & \multicolumn{2}{|c|}{1,820} & 17,114 \\
\hline $\begin{array}{l}\text { Average distances by all } \\
\text { persons (km/year) }\end{array}$ & \multicolumn{2}{|c|}{$2,185 \mathrm{~km}$} & \multicolumn{2}{|c|}{$626 \mathrm{~km}$} & \multicolumn{2}{|c|}{$3,772 \mathrm{~km}$} & \multicolumn{2}{|c|}{$385 \mathrm{~km}$} & $6,968 \mathrm{~km}$ \\
\hline
\end{tabular}

An initial descriptive analysis of the effects of the municipality population size on mode use in longdistance travel shows differences between large and small municipalities (see Table 2). Inhabitants from cities with more than 500,000 inhabitants travel more frequently, especially by train and air. Whereas about 16 percent of the inhabitants in these cities make at least one trip by train or air within the three reported months, the comparable figure for cities with less than 5000 inhabitants is only 6.3/6.6 percent. Furthermore, car use in highly populated cities is not noticeably lower.

With regard to travel distances by mobile persons (see Table 2), the descriptive analysis does not reveal differences between rural and urban populations. If a person from a less populated area travels, he or she covers similar distances to someone from the urban population. Nevertheless, the average distances covered by all persons vary due to the different levels of participation in long-distance travel. Persons from municipalities with more than 500,000 inhabitants travel on average 9641 kilometers per year, and a person from a less populated municipality travels on average only 5494 kilometers per year. This 
mainly results from more travel by train (691 kilometers per year) and air (3477). It seems that there is no substitution of long-distance travel by car (only -50 kilometers per year).

Table 2: Long-distance trips by mode and municipality population size (own calculation based on MiD 2008)

\begin{tabular}{|c|c|c|c|c|c|c|c|c|c|c|c|c|c|c|c|c|}
\hline \multirow{2}{*}{$\begin{array}{l}\text { Municipality } \\
\text { population size }\end{array}$} & \multicolumn{8}{|c|}{ Persons with at least one trip in long-distance travel } & \multicolumn{4}{|c|}{$\begin{array}{c}\text { Average distances covered by } \\
\text { mobile persons }(\mathrm{km} / \mathrm{yr})\end{array}$} & \multicolumn{4}{|c|}{$\begin{array}{c}\text { Average distances covered by } \\
\text { all persons }(\mathrm{km} / \mathrm{yr})\end{array}$} \\
\hline & to & tal & by & car & by $t$ & train & by & air & total & by car & by train & by air & total & by car & by train & by air \\
\hline$<5,000$ & 2,585 & $45.6 \%$ & 1,973 & $34.8 \%$ & 356 & $6.3 \%$ & 377 & $6.6 \%$ & 12,051 & 6,273 & 6,388 & 38,557 & 5,494 & 2,204 & 401 & 2,564 \\
\hline $5,000-<50,000$ & 7,740 & $49.2 \%$ & 5,506 & $35.0 \%$ & 1,390 & $8.8 \%$ & 1,467 & $9.3 \%$ & 13,351 & 6,159 & 5,645 & 37,501 & 6,562 & 2,154 & 498 & 3,494 \\
\hline $50,000-<500,000$ & 3,870 & $51.4 \%$ & 2,667 & $35.4 \%$ & 894 & $11.9 \%$ & 787 & $10.4 \%$ & 13,754 & 6,382 & 6,221 & 35,285 & 7,065 & 2,259 & 738 & 3,686 \\
\hline$>500,000$ & 2,919 & $55.7 \%$ & 1,767 & $33.7 \%$ & 840 & $16.0 \%$ & 823 & $15.7 \%$ & 17,317 & 6,392 & 6,819 & 38,483 & 9,641 & 2,154 & 1,092 & 6,041 \\
\hline
\end{tabular}

These findings have to be evaluated carefully. The role of socio-demographic and socioeconomic influencing factors like income and education is not considered. Inhabitants from cities have higher average incomes and education levels. Thus, the results of the descriptive analysis may be influenced by these socioeconomic characteristics.

\subsection{Multivariate analysis}

The following section presents the results that are shown in Tables 3 and 4 of this paper. Whereas the first step of the models (models $1-4,13-17$ ) produces many significant effects and Nagelkerkes $\mathrm{R}^{2}$ exceeding at least 0.1 , the linear regressions of the distances covered (models 5-8, 17-20) have very low coefficients of determination. In particular, the analysis of the distances covered on business trips shows only small effects without significance. The reasons for this are the small sample sizes and the very selective database resulting from the selection in the second step. For example, most of the business trip makers are fully employed, highly educated men with high incomes. The size of the crosschecked group is very small (e.g., there are only a very small number of persons with a very low household income who undertake long-distance trips by air). Furthermore, the socio-demographic and socioeconomic attributes used mainly have an influence on the participation, not on the distances covered. A better model might be possible if we were to have access to more occupational background information, such as profession, position in the company, or the branch.

We always present the entire model with all tested variables. We do not modify the models (stepwise adaption) because almost every explanatory variable is significant in at least one model. As the third step is a conflation of "participation in long-distance travel" (first model—selection) and "distances of mobile persons" (second model_outcome), a complete presentation of all explanatory variables is easier to understand.

Furthermore, this presentation allows a coherent progression of the ordinal variables (e.g., household income and education level) to be recognized even when some of the dummy variables next to the reference category are not significant (see Table 3, e.g., education level or density of the region). Another advantage is that if a significant difference in long-distance travel by all modes (models 1, 5, 13, 17) exists but the mode-specific models $(2-4,6-8,14-16,18-20)$ do not deliver significance, the presentation still provides information on the composition of the significant effect (e.g., Table 4, household income). 
Table 3: Regression models of long-distance travel by different modes (own calculation based on MiD 2008)

\begin{tabular}{|c|c|c|c|c|c|c|c|c|c|c|c|c|}
\hline & \multicolumn{4}{|c|}{$\begin{array}{l}\text { Participation in long-distance travel (selection } \\
\text { equation - logit model) }\end{array}$} & \multicolumn{4}{|c|}{$\begin{array}{l}\text { Distances (km/yr) of mobile persons in long- } \\
\text { distance travel (outcome equation - OLS- } \\
\text { regression) }\end{array}$} & \multicolumn{4}{|c|}{$\begin{array}{l}\text { Distances }(\mathrm{km} / \mathrm{yr}) \text { of all persons in } \\
\text { long-distance travel (descriptive OLS } \\
\text { regression) }\end{array}$} \\
\hline & Total & by car & by train & by air & Total & by car & by train & by air & Total & by car & by train $\mid$ & by air \\
\hline Mean & $50.0 \%$ & $34.8 \%$ & $10.1 \%$ & $10.0 \%$ & 13922 & 6273 & 6153 & 37345 & 6968 & 2185 & 626 & 3772 \\
\hline Respondents $(\mathrm{N})$ & 33941 & 33941 & 33941 & 33941 & 16996 & 11835 & 3447 & 3429 & 33941 & 33941 & 33941 & 33941 \\
\hline Number of Model & 1 & 22 & 3 & 44 & 5 & 6 & 77 & 88 & 9 & 10 & \begin{tabular}{c|c|}
11 \\
\end{tabular} & 12 \\
\hline $\begin{array}{l}\text { Nagelkerkes } R^{2} \\
\text { Corrected } R^{2}\end{array}$ & .156 & .138 & .101 & .120 & .080 & .052 & .044 & .021 & & & & \\
\hline Intercept & $1.043 *$ & $-.843 *$ & $-.473 *$ & $-2.011+$ & $17067 *$ & $9401 *$ & 10388 * & $29701 *$ & 14993 & 4292 & 2904 & 7780 \\
\hline \multicolumn{13}{|l|}{$\begin{array}{l}\text { Individual attributes } \\
\text { Employment - ref.: (full-time) }\end{array}$} \\
\hline $\begin{array}{l}\text { Employed - part-time } \\
\text { Non-employed }\end{array}$ & $\begin{array}{l}.055 \\
.182 *\end{array}$ & $\begin{array}{l}.115 \\
.020\end{array}$ & $\begin{array}{l}-.034 \\
-.143\end{array}$ & $\begin{array}{l}-.366 \\
-.173\end{array}$ & $\begin{array}{r}-2719 \\
-720\end{array}$ & $\begin{array}{l}-873 \\
-551\end{array}$ & $\begin{array}{l}-1990 \\
-1906\end{array}$ & $\begin{array}{r}258 \\
4120\end{array}$ & $\begin{array}{r}-1342 \\
-33\end{array}$ & $\begin{array}{l}-259 \\
-208\end{array}$ & $\begin{array}{r}-223 \\
-340\end{array}$ & $\begin{array}{r}-944 \\
44\end{array}$ \\
\hline Apprenticeship, in education & $-.604 *$ & $-1.046^{-1}$ & $.386 *$ & $-600^{-1}$ & -824 & -1420 & $-2428^{\circ}$ & 9452 & -3213 & -1944 & -94 & -1889 \\
\hline \multicolumn{13}{|c|}{ Individual attributes interactions } \\
\hline $\begin{array}{l}\text { Men } \\
40 \text { years or older } \\
\end{array}$ & $\begin{array}{l}.265 * \\
.051\end{array}$ & $.249 *$ & $\begin{array}{r}-.068 \\
-.063\end{array}$ & $\begin{array}{c}.299 * \\
-.064\end{array}$ & $\begin{array}{c}6510 * \\
-1050\end{array}$ & $\begin{array}{l}1997 * \\
-765\end{array}$ & $\begin{array}{r}760 \\
-708\end{array}$ & $\begin{array}{c}14302 * \\
559\end{array}$ & $\begin{array}{r}4663 \\
-598\end{array}$ & $\begin{array}{r}1223 \\
-389\end{array}$ & $\begin{array}{r}27 \\
-131\end{array}$ & $\begin{array}{r}3332 \\
-224 \\
\end{array}$ \\
\hline \multicolumn{13}{|c|}{ Employed - part-time - ref.: women < 40 years } \\
\hline Men & .076 & .204 & -.084 & -.146 & 2362 & 1042 & $2821 *$ & 9164 * & 1255 & 620 & 237 & 347 \\
\hline 40 years or older & .001 & -.099 & -.132 & .219 & 842 & 136 & 365 & -466 & 420 & -75 & -68 & 515 \\
\hline \multicolumn{13}{|c|}{ Non-employed - ref.: retired women $<40$ years } \\
\hline Men & .044 & .130 & -.223 & .217 & 675 * & 305 & 264 & -1554 & 313 & 146 & -50 & 184 \\
\hline 70 years or older & $-.506 *$ & $-.539 *$ & -.047 & $-.580 *$ & $-2521 *$ & $-790 *$ & -104 & -3546 & -2107 & -705 & -16 & -1265 \\
\hline Unemployed & $-.628 *$ & $-.395 *$ & -.323 & $-.746 *$ & -3286 & -319 & 1070 & -10642 & -2522 & -451 & -66 & -1589 \\
\hline Housewife /househusband & $-.252 *$ & -.079 & -.137 & -.216 & -1456 & -376 & 293 & -2892 & -1162 & -216 & 14 & -648 \\
\hline \multicolumn{13}{|c|}{ Apprenticeship, in education - ref.: female pupils older than 18 years } \\
\hline Men & .092 & .012 & .079 & .050 & -1976 & 59 & 324 & -9727 & -732 & 23 & 114 & -838 \\
\hline In apprenticeship & -.211 & .238 & $-.688 *$ & -.106 & -31 & 1204 & 311 & 2478 & -592 & 554 & -473 & -79 \\
\hline University students & $.514 *$ & $.724 *$ & -.032 & $.633 *$ & 2231 & 752 & 1019 & -1343 & 2751 & 979 & 289 & 2127 \\
\hline \multicolumn{13}{|c|}{ Education Level (only persons who finished education) - ref.: University grade } \\
\hline University entrance qualification & $-.401 *$ & $-287 *$ & $-291 *$ & $-250 *$ & $-2316 *$ & -273 & -935 & -4604 & -3056 & -630 & -372 & -2042 \\
\hline Secondary school q. & $-.716 *$ & $-.497 *$ & $-.678 *$ & $-.554 *$ & $-3501 *$ & $-711 *$ & $-1034 *$ & -3700 & -4591 & -1065 & -572 & -2954 \\
\hline Basic school or no qualification & $-1.120 *$ & $-.915 *$ & $-1.126 *$ & $-.880 *$ & $-4549 *$ & $-761 *$ & $-1320 *$ & -7470 & -5813 & -1474 & -700 & -3583 \\
\hline \multicolumn{13}{|l|}{$\begin{array}{l}\text { Household attributes } \\
\text { Household income - ref.: very high }\end{array}$} \\
\hline High & $-.455 *$ & $-.243 *$ & $-.294 *$ & $-.475 *$ & $-5562 *$ & $-908 *$ & -866 & -5194 & -5776 & -924 & -392 & -4441 \\
\hline Medium & $-.795 *$ & $-.492 *$ & $-.486 *$ & $-.872 *$ & $-7494 *$ & $-1550 *$ & $-1130 *$ & -6457 & -7829 & -1502 & -515 & -5753 \\
\hline Low & $-1.064 *$ & $-.742 *$ & $-.699 *$ & $-1.142 *$ & $-9214 *$ & $-1891 *$ & -1283 & -11508 & -9088 & -1826 & -639 & -6467 \\
\hline Very low & $-1.274 *$ & $-.914 *$ & $-.763 *$ & $-1.455 *$ & $-7933 *$ & $-1607 *$ & -1024 & -508 & -8626 & -1842 & -582 & -6009 \\
\hline \multicolumn{13}{|c|}{ Motorisation of the household - ref:: no car } \\
\hline part-motorised & $.410 *$ & $1.313 *$ & $-.843 *$ & $.403 *$ & 382 & -146 & -123 & -1212 & 576 & 766 & -641 & 356 \\
\hline full-motorised & $.371 *$ & $1.343 *$ & $-1.104 *$ & . & $2403 *$ & 493 & -169 & 4012 & 1558 & 1082 & -796 & 1201 \\
\hline \multicolumn{13}{|c|}{ Household type - ref.: Single-person household < 40 years } \\
\hline Singles, $40-69$ years & $-643 *$ & $-.623 *$ & -.134 & -.121 & 36 & $-1816 *$ & -651 & 2359 & -1904 & -1310 & -514 & 11 \\
\hline Singles, 70 years or older & $-.681 *$ & $-.673 *$ & -.443 & -.566 & $-2278 *$ & $-3337 *$ & -1418 & -1402 & -2195 & -1045 & -906 & -294 \\
\hline Multi-person household & $-.382 *$ & \begin{tabular}{l|l|}
-.207 \\
\end{tabular} & $-.468 *$ & -.135 & -476 & $-1740 *$ & -878 & 4137 & -1344 & -768 & -745 & 123 \\
\hline with child/ren & .004 & .059 & -.021 & -.022 & 381 & 138 & -256 & 1904 & 287 & 153 & -30 & 257 \\
\hline \multicolumn{13}{|c|}{$\begin{array}{l}\text { Spatial attributes at the residence } \\
\text { Municipality population size - ref.: }<5,000 \text { inhabitants }\end{array}$} \\
\hline $5,000-<50,000$ inhabitants & .024 & .066 & $251 *$ & .159 & 369 & -352 & -795 & -185 & 189 & -202 & 28 & 315 \\
\hline $50,000-<500,000$ inhabitants & .050 & -.029 & $.268 *$ & $.304 *$ & 29 & -142 & -460 & $-7475 *$ & 99 & -90 & 76 & 148 \\
\hline$\nabla=500,000$ inhabitants &.$\overline{432} \bar{*}$ & $.028^{-}$ & $.907^{*} *$ & $1.175^{-*}$ & $6333 *$ & -81 & $-376^{-}$ & 3925 & $432 \overline{8}$ & $-5 \overline{9}$ & $49 \overline{4}$ & $38 \overline{11}$ \\
\hline \multirow{2}{*}{\multicolumn{13}{|c|}{$\begin{array}{l}\text { Spatial attributes at the residence interactions } \\
\text { Density of the region (only municipalities }<500.000 \text { inhabitants) - ref:: Rural areas }\end{array}$}} \\
\hline \multicolumn{6}{|c|}{ Density of the region (only municipalities $<500.000$ inhabitants) - ref.: Rural areas } & & & & & & & \\
\hline urbanised area & .048 & .009 & .136 & .194 & 1272 & -83 & -531 & 4164 & 775 & -8 & 32 & 689 \\
\hline agglomeration area & $.123 *$ & .048 & .068 & $.470 *$ & $2351 *$ & $291 *$ & -476 & 2103 & 1541 & 177 & 3 & 1299 \\
\hline Accessibility of inter-urban rail static & cipalities $<50$ & 0.000 inhab & tants)- ref.: > & $>30$ minutes & by car & & & & & & & \\
\hline $10-<30$ minutes by car & $.156 *$ & .082 & $.282 * 1$ & $.197 *$ & 860 & 0 & 39 & -769 & 699 & 75 & 104 & 436 \\
\hline$<10$ minutes by car & $.181 *$ & .095 & $.421 *$ & .111 & 1937 & 72 & 114 & 7815 & 1331 & 129 & 200 & 894 \\
\hline
\end{tabular}


Table 4: Regression models of long-distance business travel by different modes (own calculation based on MiD 2008)

\begin{tabular}{|c|c|c|c|c|c|c|c|c|c|c|c|c|}
\hline & \multicolumn{4}{|c|}{$\begin{array}{l}\text { Participation in long-distance business travel } \\
\text { (selection equation - logit model) }\end{array}$} & \multicolumn{4}{|c|}{$\begin{array}{l}\text { Distances (km/yr) of mobile persons in long- } \\
\text { distance business travel (outcome equation - } \\
\text { OLS-regression) }\end{array}$} & \multicolumn{4}{|c|}{$\begin{array}{l}\text { Distances (km/yr) of all persons in } \\
\text { long-distance business travel } \\
\text { (descriptive OLS regression) }\end{array}$} \\
\hline & Total & by car & by train & by air & Total & by car & by train & by air & Total & by car & by train & by air \\
\hline Mean & $8.5 \%$ & $4.8 \%$ & $2.4 \%$ & $2.2 \%$ & 21040 & 8858 & 7738 & 51162 & 1786 & 433 & 190 & 1127 \\
\hline Respondents (N) & 33941 & 33941 & 33941 & 33941 & 2876 & 1657 & 833 & 746 & 33941 & 33941 & 33941 & 33941 \\
\hline Number of model & 13 & 14 & 15 & 16 & 17 & 18 & 19 & 20 & 21 & 22 & 23 & 24 \\
\hline Nagelkerkes $\mathrm{R}^{2}$ & .312 & .255 & .204 & .289 & & & & & & & & \\
\hline Corrected R2 & & & & & .078 & .066 & .029 & .022 & & & & \\
\hline Intercept & $-1.149 *$ & $-3.052 *$ & $-1.847 *$ & -3.024 * & $2205 *$ & 13897 * & $12177 *$ & 29701 * & 4159 & 1209 & 1101 & 7780 \\
\hline \multicolumn{13}{|l|}{$\begin{array}{l}\text { Individual attributes } \\
\text { Employment - ref.: (full-time) }\end{array}$} \\
\hline Employed - part-time & $-.900 *$ & $-1.076 *$ & $-.769 *$ & $-1.068 *$ & 368 & -1702 & -3810 & 22569 & -1076 & -453 & -253 & -422 \\
\hline Non-employed & -2.343 & $-2.366 *$ & $-2.247 *$ & $-2.426 *$ & 1369 & 583 & -537 & 9505 & -609 & -371 & -269 & 14 \\
\hline Apprenticeship, in education & $-2.888 *$ & $-3.023^{-1}$ & -2.628 * & $-3.244 * 7$ & $-8 \overline{93}$ & $-16 \overline{3} 4$ & $-\overline{43} \overline{56}$ & $-35 \overline{8} 2 \overline{2}$ & $-27 \overline{3}$ & $-\overline{63} 8$ & -554 & $-1 \overline{6} 2 \overline{3}$ \\
\hline \multicolumn{13}{|c|}{$\begin{array}{l}\text { Interactions between individual attributes } \\
\text { Employed - full-time - ref.: women }<40 \text { years }\end{array}$} \\
\hline Men & $1.032 *$ & $1.134 *$ & $.435 *$ & $.983 *$ & $12456 *$ & $4554 *$ & 834 & $29727 *$ & 4592 & 1198 & 188 & 3090 \\
\hline 40 years or older & $-.185 *$ & $-.230 *$ & -.074 & -.033 & 1827 & -482 & -210 & 5439 & -286 & -338 & -68 & 89 \\
\hline \multicolumn{13}{|c|}{ Employed - part-time - ref.: women $<40$ years } \\
\hline Men & $.846 *$ & $1.211 *$ & .376 & .729 & 4946 & 5314 & 2091 & $13880 *$ & 1166 & 461 & 62 & 636 \\
\hline 40 years or older & -.094 & -.042 & .044 & -.243 & 3472 & 37 & 801 & 20346 & 413 & 41 & 22 & 377 \\
\hline \multicolumn{13}{|c|}{ Apprenticeship, in education - ref.: female pupils older than 18 years } \\
\hline Men & .030 & -.063 & .032 & .280 & 3078 & 966 & 1657 & 22397 & 123 & 29 & 20 & 85 \\
\hline In apprenticeship & $2.004 *$ & $2.280 *$ & $1.743 *$ & 1.027 & 3415 & 276 & -188 & 20913 & 532 & 135 & 131 & 264 \\
\hline University students & $1.806 *$ & 1.202 & $1.892 *$ & $2.076 *$ & 12063 & 2159 & 2240 & 32087 & 947 & 97 & 225 & 620 \\
\hline \multicolumn{13}{|c|}{ Education Level (only persons who finished education) - ref.: university grade } \\
\hline University entrance qualification & $-.449 *$ & -.213 & $-.711 *$ & $-.431 *$ & -1932 & -474 & -408 & -849 & -1551 & -187 & -259 & -1107 \\
\hline Secondary school q. & $-.980 *$ & $-.620 *$ & $-1.258 *$ & $-1.222 *$ & -985 & 982 & -516 & 13994 & -2155 & -254 & -318 & -1595 \\
\hline Basic school or no qualification & $-1.496 *$ & $-1.148 *$ & $-2.102 *$ & $-1.848 *$ & -5307 & 1459 & -1962 & -7453 & -2275 & -329 & -326 & -1634 \\
\hline \multicolumn{13}{|l|}{$\begin{array}{l}\text { Household attributes } \\
\text { Household income - ref.: very high }\end{array}$} \\
\hline High & $-.462 *$ & $-.320 *$ & $-.314 *$ & $-.698 *$ & $-4440 *$ & $-1612 *$ & -1323 & 663 & -2402 & -388 & -218 & -1843 \\
\hline Medium & $-.807 *$ & $-.562 *$ & $-.651 *$ & $-1.180 *$ & $-5281 *$ & $-1572 *$ & -1530 & 8059 & -2785 & -471 & -280 & -2059 \\
\hline Low & $-.847 \star$ & $-.642 *$ & $-.762 *$ & $-1.294 *$ & $-8986 *$ & $-3266 *$ & -581 & 4734 & -3216 & -567 & -292 & -2390 \\
\hline Very low & $-1.213 *$ & $-1.040 *$ & $-.972 *$ & $-2.068 *$ & -411 & 830 & -361 & 76569 & -2558 & -478 & -262 & -1855 \\
\hline \multicolumn{13}{|c|}{ Motorisation of the household - ref.: no car } \\
\hline $\begin{array}{l}\text { part-motorised } \\
\text { full-motorised }\end{array}$ & $\begin{array}{r}-.034 \\
.146 \\
\end{array}$ & $\begin{array}{r}.833 * \\
1.218 *\end{array}$ & $\begin{array}{l}-.544 * \\
-.847 *\end{array}$ & $\begin{array}{l}.052 \\
.238\end{array}$ & $\begin{array}{l}12 / 2 \\
4941\end{array}$ & $\begin{array}{l}-2417 \\
-2616 *\end{array}$ & $\begin{array}{l}-350 \\
-773 \\
\end{array}$ & $\begin{array}{r}3436 \\
15630 \\
\end{array}$ & $\begin{array}{r}-346 \\
211\end{array}$ & $\begin{array}{r}-50 \\
112\end{array}$ & $\begin{array}{r}-101 \\
-171\end{array} \mid$ & $\begin{array}{r}-200 \\
249\end{array}$ \\
\hline \multicolumn{13}{|c|}{ Household type - ref.: Single-person household < 40 years } \\
\hline Singles, $40-69$ years & -.211 & -.073 & -.209 & -.449 & -5841 & -1566 & -1579 & -9803 & -599 & -71 & -256 & -239 \\
\hline Singles, 70 years or older & -.983 & -.327 & -1.995 & $-.812 *$ & -4946 & -6022 & -2755 & 9056 & -25 & 19 & -324 & 312 \\
\hline Multi-person household & -.231 & .065 & -.497 & -.412 & 1187 & -1183 & -557 & 11992 & -140 & 9 & -280 & 156 \\
\hline with child/ren & $.386 *$ & $.265 *$ & $.305 *$ & .734 & 5772 & -123 & -646 & 4820 & 1379 & 111 & 51 & 1234 \\
\hline \multicolumn{13}{|c|}{ Spatial attributes at the residence } \\
\hline \multicolumn{13}{|c|}{ Municipality population size - ref.: $<5,000$ inhabitants } \\
\hline $5,000-<50,000$ inhabitants & -.011 & -.151 & .251 & .130 & 1203 & -1671 & -603 & 9842 & 100 & -154 & 18 & 210 \\
\hline $50,000-<500,000$ inhabitants & .012 & -.039 & .120 & .247 & 677 & -1510 & -695 & 1123 & 66 & -112 & 3 & 177 \\
\hline$>=500,000$ inhabitants & $.405 *$ & -.256 & $1.032 *$ & $-1.230 *$ & 11865 & $-482 \overline{1}$ & -868 & $34 \overline{5} 3 \overline{2}$ & 1536 & -312 & 196 & 1634 \\
\hline \multicolumn{13}{|c|}{\begin{tabular}{|l|l|} 
Interaction between spatial attributes at the residence &
\end{tabular}} \\
\hline \multicolumn{13}{|c|}{ Density of the region (only municipalities $<500.000$ inhabitants) - ref.: Rural areas } \\
\hline urbanised area & .105 & .060 & .186 & .107 & 1982 & -1587 & -374 & 18277 & 306 & -38 & 25 & 297 \\
\hline agglomeration area & .128 & .051 & .107 & .389 & 3350 & -1582 & -875 & 13408 & 495 & -32 & 4 & 503 \\
\hline \multicolumn{13}{|c|}{ Accessibility of inter-urban rail station (only municipalities $<500.000$ inhabitants)- ref.: $>30$ minutes by car } \\
\hline $10-<30$ minutes by car & .136 & .022 & $.393 *$ & .282 & 1969 & -928 & -990 & 8055 & 238 & -36 & 26 & 257 \\
\hline$<10$ minutes by car & .187 & -.022 & $.687 *$ & .174 & 5898 & -473 & -1051 & 26673 & 660 & -23 & 78 & 588 \\
\hline
\end{tabular}

The analysis is informative and allows the hypotheses stated in this paper to be addressed. The control hypotheses $2-4$ should verify the role of well-known socio-demographic and socioeconomic influencing factors. Most parts of these hypotheses can be confirmed.

- As mentioned above, significant effects are mainly found in the first step of the analysis. Only the socioeconomic variables education level and household income differ. Persons with a lower 
household income and/or a lower education level travel less and not as far as persons with a higher income and/or a higher education level. These differences are found both in business travel (see Table 4) and in private travel (difference between Tables 4 and 3) and refer to every mode. We control our analysis by using interaction terms between education level and household income. The effects of this analysis are weak and not significant. It can be assumed that both attributes work independently and are mostly additive.

- Education level and household income are significant influencing factors in all logistic regressions. Persons with a high income travel on average 9000 kilometers more than those with a low income (model 3). There is a difference of about 5800 kilometers between those of the highest and the lowest education level. This gap is recognizable for every mode and is already obvious during the period of education. University students travel more frequently by car and by air than apprentices.

- Employment does not show effects as strong as the household income or the education level. When both private and business travel are analyzed there are only small differences between fully employed, partly employed, and non-employed persons. These differences become much higher when the focus is on business travel. Fully employed persons mainly undertake business travel. Accordingly, they use every mode more frequently.

- The gender gap still exists. In long-distance travel the differences are found only in business travel. Compared to employed women, employed men undertake more long-distance trips by car and especially by air.

- Household size as an influencing factor is not very strong. There are differences in car use between single households with persons under the age of 40 and single households with older persons. Single households of young persons are the group that covers the most kilometers by car in long-distance travel, even more than multi-person household members (-768 kilometers). As expected, these differences exist only in private travel. In contrast, the presence of a child in the household shows a significant positive effect on participation in business travel with all modes.

- Finally, car availability leads to more trips by car at the expense of trips by train. Thereby, the number of cars in the household only has an impact on participation by car and train in business travel. This is understandable because private trips are mostly undertaken together with the household and thus require only one car.

After verifying the control hypotheses, we focus on hypothesis one. It was assumed that an urban population with access to a well-developed public transport system participates more frequently in longdistance trips than does the rural population. According to this hypothesis, the difference in travel frequency should result from a higher use of the public transport system. Three explanatory variables are included in the analysis. The first one is a differentiation according to the population size of the municipality. The analysis reveals that individuals from the highly populated cities in Germany tend to undertake more long-distance trips. This difference mainly results from a higher number of trips by train and by airplane. A person from a city with more than 500,000 inhabitants covers an average of about 4300 kilometers more than a person from a city with less than 500,000 inhabitants. This is a result of more private and more business travel. Regarding the mode use, trips by air and by train are the main reasons for the differences found. In contrast to hypothesis two, but not contrary to our expectations, the urban population does not dispense with long-distance car trips. It should be noted that the analysis includes household motorization as a control variable. If car accessibility were not considered, the differences in household motorization would influence the effects of the spatial attributes.

The findings are supported by the analysis of the second explanatory variable. Using only the municipalities with less than 500,000 inhabitants, there are still measureable differences between agglomerations and other less dense areas. In agglomerations inhabitants use the airplane more frequently, 
which leads to more long-distance trips in total. No differences are found between medium-dense areas (urbanized areas) and rural areas. The analysis of business travel also reveals no significant differences. We use the accessibility of an inter-urban rail station as a centrality rating. The results of this variable are as expected.

The accessibility of an inter-urban rail station promotes the use of the train considerably. Our analysis does not show a compensation strategy whereby good accessibility of an inter-urban rail station decreases the amount of trips by car or by air. On the contrary, the use of the car and airplane slightly increases with better accessibility, but the effects do not become significant. It may be that there is a correlation between accessibility to a train station and accessibility to an airport. It can be assumed that these effects also apply to airport infrastructure.

To sum up, we note that urban structures with well-developed public transport infrastructure increase the probability of a higher use of the public transport system (including airplanes). However, the analysis does not show that the built environment has any influence on car travel. These results are found for private and business travel.

\section{Conclusion and outlook}

This paper emphasizes the relevance of mode use in long-distance travel. The results widely support the stated hypotheses. Among the variables analyzed, socioeconomic attributes like household income, level of education and, for business trips, also gender are seen to be significant influencing factors on longdistance travel behavior. In addition, the findings of Holz-Rau, Scheiner and Sicks (2014) regarding the influence of the built environment are confirmed.

The analysis proves some well-known facts but in addition reveals new findings concerning differences in mode use in long-distance travel between urban and rural populations. An urban lifestyle seems to encourage people to undertake more long-distance trips, especially to make use of airplanes and trains more frequently. These differences are not only restricted to business travel. It also can be concluded from the analysis that private travel shows the same tendencies. This strengthens the "escape trip" hypothesis, which is supported by the research of Heinonen et al. (2013) and also of Brand and Preston (2010). Furthermore, it can be assumed that urban dwellers tend to have a more widely spread social network.

Next to well-known socioeconomic influencing factors like household income, education level has emerged as another strong influencing factor. Those with a university degree travel more frequently and farther than individuals with a lower education level. The reason for this might be better language skills or more widespread social networks established during the period of education or employment (Frei and Axhausen 2007). It has to be mentioned that the number of persons with university entrance qualifications or university degrees has increased in recent years in Germany. Between 1991 and 2012 the percentage of persons with a university entrance qualification nearly doubled (1991: 15.1 percent; 2012: 27.3 percent; Destatis 2013). If future generations of highly educated persons adopt the lifestyle of the highly educated of today, a lot more long-distance travel has to be expected in the future.

Even today, in Germany more than 50 percent of climate impact through passenger transport is caused by long-distance travel (Aamaas, Borken-Kleefeld, and Peters 2013). Regarding recent developments, this percentage is set to increase, thus also increasing the importance of measures to control pollution, especially from airplanes. Furthermore, it is essential to expand the analysis conducted here. A more detailed description of the spatial setting is desirable. The inclusion in this study of consideration of access to an inter-urban rail station is an improvement on previous analyses. However, the design of this attribute in the $\mathrm{MiD}$ should be enhanced, because it only measures the distance from the center of one municipality to another. This measurement can be rendered more specific by calculating the real 
distance between the residential location and the train station. In addition, the distance is estimated as minutes by car, which does not consider other travel modes.

As already stated by Holz-Rau, Scheiner and Sicks (2014), further open questions refer to the role of lifestyles, values, and preferences concerning long-distance travel. These aspects play an important part in residential choices and daily travel behavior (Scheiner 2010). Unfortunately, the MiD provides no information suitable for dealing with these open questions.

One of the next steps is to achieve deeper insight into the ecological consequences of travel. Therefore, the subsequent aim is an extrapolation of emissions, or climate impact, caused by daily and longdistance travel. This would also allow a comparison between both types of travel with regard to the environmental consequences. In addition, an aggregation of emissions by daily and long-distance travel could provide a summarized view of the climate impact of passenger transport in Germany. Furthermore, it would be helpful to identify socio-demographic, socioeconomic, and spatial influencing factors that lead to particularly environmentally harmful travel behavior. Nevertheless, an analysis of emissions cannot replace analysis of the mode use. Regarding this analysis, we can identify characteristics that promote or restrain the use of a mode.

In short: The better-educated and wealthy urban population is cosmopolitan and thus travels around the world. The group's urban mode is the plane. This is a clear but careful formulation, giving no information about causes. On the basis of our data, we cannot make reliable statements on causes, but our view of the spatially differentiated social developments suggests that mental and physical cosmopolitanism is not only based on the built environment. It is also an expression of modern life in metropolitan regions. The differences give, to put it in a nutshell, "a look at the future of transportation," also for other regions. It becomes quite clear that in future research consideration of long-distance travel and, in particular, air travel will be very important for sustainable development.

\section{Acknowledgments}

This analysis was funded by the German Research Foundation (DFG). Additionally, we want to thank three anonymous reviewers for their comments and suggestions.

\section{References}

Aamaas, B., J. Borken-Kleefeld, and G. Peters. 2013. The climate impact of travel behavior: A German case study with illustrative mitigation options. Environmental Science and Policy 33: 273-282.

Addante, E. 2001. Air travel market segments-A New England case study. Transportation Research Circular E-C026-Personal Travel: The Long and Short of It, 307-319.

Bagley, M.N., and P. L. Mokhtarian. 2002. The impact of residential neighborhood type on travel behavior: A structural equation modeling approach. The Annals of Regional Science 36: 297-297.

Boussauw K., and F. Witlox. 2011. Linking expected mobility production to sustainable residential location planning: Some evidence from Flanders. Journal of Transport Geography 19: 936-942.

Brand, C., and J. M. Preston. 2010. 60-20 emission-The unequal distribution of greenhouse gas emissions from personal, non-business travel in the UK. Transport Policy 17: 9-19.

Brownstone, D., and T. F. Golob. 2009. The impact of residential density on vehicle usage and energy consumption. Journal of Urban Economics 65: 91-98.

Brög, W., E. Erl, G. Sammer, and B. Schulze. 2003. DATELINE—Design and application of a travel survey for long-distance trips based on an International network of expertise-concept and methodology. 10th International Conference on Travel Behavior. August 10-15, 2003, Lucerne, 
Switzerland. http://www.ivt.ethz.ch/news/archive/20030810_IATBR/broeg.pdf.

Brüderl J. 2000. Regressionsverfahren in der Bevölkerungswissenschaft. Unpublished manuscript. Munich, Germany. http://www.sowi.uni-mannheim.de/lsssm/papers/Regressionsverfahren.pdf.

Bühler, R., and U. Kunert. 2008. Trends and Determinants of Travel Behavior in the USA and in Germany. Berlin: BMVBS (Federal Ministry of Transport, Building and Urban Development). http:// ralphbu.files.wordpress.com/2011/09/bmvbs.pdf.

Crane, R. 2007. Is there a quiet revolution in women's travel? Revisiting the gender gap in commuting. American Planning Association 73: 298-316.

Destatis (Federal Statistical Office of Germany). 2013. Bildungsstand der Bevölkerung. Wiesbaden, Germany: Destatis. https://www.destatis.de/DE/Publikationen/Thematisch/BildungForschungKultur/Bildungsstand/BildungsstandBevoelkerung5210002137004.pdf?_blob=publicationFile.

Frändberg, L. 2009. How normal is traveling abroad? Differences in transnational mobility between groups of young Swedes. Environment and Planning A 41: 649-671.

Frändberg, L., and B. Vilhelmson. 2003): Personal mobility: A corporal dimension of transnationalisation-The case of long-distance travel from Sweden. Environment and Planning A 35: 1751-1768.

Frei, A., and K. W. Axhausen. 2007. Size and Structure of Social Network Geographies. Zurich: ETH University of Technology.

Frick, R., and B. Grimm. 2014. Long-Distance Mobility—Current Trends and Future Perspectives. Munich: NIT_Institute for tourism research in Northern Europe. http://www.ifmo.de/tl_files/ publications_content/2014/ifmo_2014_Long_Distance_Mobility_en.pdf

Georggi, N., and R. Pendyaja. 2001. Analysis of long-distance travel behavior of the elderly and low income. Transportation Research Circular E-C026-Personal Travel: The Long and Short of It,121150 .

Heinonen, J., M. Jalas, J. K. Juntunen, S. Ala-Mantila, and S. Junnila. 2013. Situated lifestyles: I. How lifestyles change along with the level of urbanization and what the greenhouse gas implications are- a study of Finland. Environmental Research Letters 8, 025003.

Hjorthol, R. 2008. Daily mobility of men and women-A Barometer of Gender Equality? Gendered Mobilities, edited by T. P. Uteng and T. Cresswell. Aldershot: Ashgate. 193-209.

Holden, E., and K. Linnerud. 2011. Troublesome leisure travel: The contradictions of three sustainable transport policies. Urban Studies 48: 3087-3106.

Holm, S. 1979. A simple sequentially rejective multiple test procedure. Scandinavian Journal of Statistics 6: 65-70.

Holz-Rau, C., J. Scheiner, and K. Sicks. 2014. Travel distances in daily travel and long-distance travel: Which role is played by urban form? Environment and Planning A 46: 488-507.

INFAS (Institut für angewandte Sozialwissenschaft), and DLR (National Aeronautics and Space Research Center of the Federal Republic of Germany. 2010. Mobilität in Deutschland_Methodenbericht. http://www.mobilitaet-in-deutschland.de/02_MiD2008/publikationen.htm

KITE (A knowledge base for intermodal passenger travel in Europe). 2008. Deliverable D4: Relevant Market Segments in Intermodal Passenger Travel. http://kite-project.eu/kite/cms/images/stories/ kite/WP2/D4\%20-\%20Relevant\%20Market\%20Se gments\%20in\%20Intermodal\%20 Passenger\%20Travel.pdf

Korbetis, M., D. S. Reay, and J. Grace. 2006. New directions: Rich in $\mathrm{CO}^{2}$. Atmospheric Environment 40: 3219-3220.

Kennedy, P. 2010. A Guide to Econometrics. Malden, UK: Blackwell Publishing.

Limtanakool, N., M. Dijst, and T. Schwanen. 2006. On the participation in medium- and longdistance travel: A decomposition analysis for the UK and the Netherlands. Tijdschrift voor Econo- 
mische en Sociale Geografie 97: 389-404.

Mallet, W. J. 2001. Long-distance travel by low-income households. Transportation Research Circular E-C026-Personal Travel: The Long and Short of It, 169-177.

Martín, J.C., R. Concepción, J. C. Garcia-Palomares, and J. Gutiérrez. 2014. Spatial analysis of the competitiveness of the high-speed train and air transport: The role of access to terminals in the Madrid-Barcelona corridor. Transportation Research A 69: 392-408.

Mokhtarian, P., and X. Cao. 2008. Examining the impacts of residential self-selection on travel behavior: A focus on methodologies. Transportation Research Part B 42: 204-228.

Naess, P. 2011. New urbanism or metropolitan-level centralization. Journal of Transport and Land Use 4: $25-44$.

Scheiner, J. 2010. Social inequalities in travel behavior: Trip distances in the context of residential selfselection and lifestyles. Journal of Transport Geography 18: 679-690

Schlich, R., and S. Schönfelder. 2001. Zwei Sichten der Aktivitätenteilnahme. Tagebücher und Aktivitätenhäufigkeitsbögen. AMUS 2001-Tagungsband zum 2. Aachener Kolloquium Mobilität und Stadt, edited by K. J. Beckman, p. 147-163. Aachen, Germany: Stadt Region Land 71.

Stead, D., J. Williams, and H. Titheridge. 2000. Land use, transport and people: Identifying the connections. In Achieving Sustainable Urban Form, edited by K. Williams, E. Burton, and M. Jenks, 174-186. New York: Spon Press.

Stewart, J. 2009. Tobit or not tobit? Washington DC: Bureau of Labor Statistics. http://www.bls.gov/ ore/pdf/ec090100.pdf

Van Acker, V., and F. Witlox. 2010. Car ownership as a mediating variable in car travel behavior research using a structural equation modeling approach to identify its dual relationship. Transport Geography 18: 65-74.

Van Acker, V., F. Witlox, and B. van Wee. 2007. The effects of land use system on travel behavior: A structural equation modeling approach. Transport Planning and Technology 30: 331-353.

Wiedenhofer, D., M. Lenzen, and J. K. Steinberger. 2013. Energy requirements of consumption: Urban form, climatic and socio-economic factors, rebounds and their policy implications. Energy Policy 63: 696-707.

Winship C., and R. D. Mare. 1992. Models for sample selection bias. Annual Review of Sociology 18: 327-350.

Wooldridge, J. M. 2013. Introductory Econometrics. Mason, OH: South-Western Cengage Learning.

Zhang, M. 2004. The role of land use in travel mode choice. Evidence from Boston and Hong Kong. Journal of American Planning Association 70: 34-360.

Zumkeller, D., W. Manz, J. Last, and B. Chlond. 2005. Die intermodale Vernetzung von Personenverkehrsmitteln unter Berücksichtigung der Nutzerbedürfnisse (INVERMO)—Schlussbericht. Karlsruhe, Germany: Institut für Verkehrswesen, Universität Karlsruhe. 